\title{
Change in the Height of the Medial Longitudinal Plantar Arch according to the Distance between the Knees While Performing Squats
}

\author{
Sung-dae Choung, Ph.D.; Ju-yoon Kim, BS \\ Department of Physical Therapy, Division of Health Science, Baekseok University, Cheonan, South Korea
}

Background The squat is not only used for training purposes in many sports, but also for rehabilitation after knee surgery, such as cruciate ligament repair surgery. However, when the squatting posture becomes unstable during the exercise or the body alignment changes, it can cause injury to the back or knees.

Purpose This study examined the change in height of the medial longitudinal plantar arch according to the distance between the knees while performing squats.

Study design Pre/post-test design.

Methods The subject maintained a squat against a wall, with the hips and knees at 90 degrees. The distance between the knees was the independent variable: two-, three, and four-thirds of the pelvic width. We measured the navicular drop in the three squatting stances.

Results The navicular drop differed significantly among the three conditions.

Conclusions Changing the distance between the knees while squatting affects the medial longitudinal plantar arch. Clinicians should educate their patients on the correct squat position.

Key words Medial longitudinal plantar arch; Navicular tuberosity; Squatting.

\author{
Journal of KEMA \\ 2018; 2(1): 24-27 \\ Published Online \\ June 30, 2018 \\ pISSN: $2586-4351$ \\ eISSN: 2586-5706 \\ Article History \\ Received 19 April 2018 \\ Revised 30 April 2018 \\ Accepted 01 May 2018

\section{CONTACT} \\ dae282282@bu.ac.kr \\ Sung-dae Choung, \\ Department of Physical \\ Therapy, Division of \\ Health Science, Baekseok \\ University, Cheonan, \\ South Korea

$$
\begin{aligned}
& \text { This is an Open-Access article } \\
& \text { distributed under the terms of } \\
& \text { the Creative Commons Att- } \\
& \text { ribution Non-Commercial Li- } \\
& \text { cense (http://creativecommons. } \\
& \text { org/licenses/by-nc/4.0) which } \\
& \text { permits unrestricted non-co- } \\
& \text { mmercial use, distribution, and } \\
& \text { reproduction in any medium, } \\
& \text { provided the original work is } \\
& \text { properly cited. }
\end{aligned}
$$

\section{INTRODUCTION}

The squat is not only used for training purposes in many sports, but also for rehabilitation after knee surgery, such as cruciate ligament repair surgery. ${ }^{1}$ However, when the squatting posture becomes unstable during the exercise or the body alignment changes, it can cause injury to the back or knees. $^{2,3}$

Particularly, on changing the foot position, a pronated foot increases the tibial medial torsion and alters the knee alignment, which could lead to knee dislocation or quadriceps imbalance. ${ }^{4}$ Excessive pronation of the subtalar joint may reduce the shock-absorbing capacity of the foot, resulting in a compensatory weight load on the knee. ${ }^{5}$ A decrease in the medial longitudinal arch of the foot could induce a shortened leg length, resulting in compensatory internal rotation of the hip, increased iliopsoas muscle tone, and anterior tilt of the pelvis and lumbar spine. ${ }^{6,7}$

Park and $\mathrm{Nam}^{8}$ showed that when squatting was performed while forming a normal medial longitudinal plantar arch, the activities of the abductor hallucis, fibularis longus, and gluteus medius muscles were significantly increased compared with squatting with an abnormal medial longitudinal plantar arch. Therefore, any change in the mechanical arrangement of the foot is an important factor while squatting.

To be able to explain the importance of posture while squatting to people who lack detailed anatomical knowledge, clinicians should study the squatting posture. However, few studies have examined the relationship between the distance between the knees and the medial longitudinal plantar arch 
during squatting. Therefore, we studied changes in the medial longitudinal plantar arch when performing squats with various distances between the knees.

\section{METHODS}

\section{Participants}

We recruited 18 subjects from Chungnam B University. The subjects had no problems with walking, running, or engaging in sports activities. The subjects' age, weight, height, pelvic width, and height of the medial longitudinal plantar arch were determined. After explaining the experimental process, the subjects provided informed consent before participating in the experiment. Their characteristics are listed in Table 1.

\section{Measurement of medial longitudinal plantar arch}

We measured the medial longitudinal plantar arch with a ruler placed perpendicular to the ground; the height of the navicular tuberosity from the floor was measured.

\section{Procedure}

The height of the medial longitudinal plantar arch of each subject was measured during four conditions. The distance between the navicular tuberosity and the floor was measured while in the sitting position (non-weight bearing), and in three squatting positions while against a wall with the hips and knees at 90 degrees: the knees were separated by two-, three-, and four-thirds of the pelvic width. The height of the medial longitudinal plantar arch was measured three times.

\section{Statistical analysis}

Repeated-measures analysis of variance (ANOVA) was

Table 1. Characteristics of subjects $(\mathrm{N}=18)$

\begin{tabular}{ccc}
\hline Variable & Mean & Standard deviation \\
\hline Age $(\mathrm{yrs})$ & 168.9 & 8.40 \\
Weight $(\mathrm{kg})$ & 21.4 & 2.15 \\
Height $(\mathrm{cm})$ & 63.1 & 12.35 \\
\hline
\end{tabular}

used to determine the significance of differences between the dependent variables, and the Bonferroni procedure was used for the post-hoc analysis. All of the continuous variables were found to approximate a normal distribution (Kolmogorov-Smirnov $\mathrm{Z}$ test, $p>0.05$ ). All statistical analyses were performed using PASW software ver. 18.0 (SPSS, Inc., Chicago, IL, USA), and the level of statistical significance was set at 0.05 .

\section{RESULTS}

The height of medial longitudinal plantar arch differed significantly when squatting was performed with the knees separated by two-, three-, or four-thirds of the pelvic width (Table 2).

\section{DISCUSSION}

In today's society, people are increasingly health conscious and participate in various activities to promote health, such as weight training programs. ${ }^{9,10}$ The squat is a basic exercise for the lower extremity muscles that also increases bone density and ligament and tendon strength, and strengthens the muscles of the trunk and buttocks, which are important for running and lifting movements. ${ }^{11}$ The squat is a good closed chain movement exercise that can minimize stress on the anterior cruciate ligament through contraction of the quadriceps and hamstrings, and thus contribute to the stability of the knee joint. ${ }^{12}$

To determine the correct posture for performing squats, this study examined the effect of the distance between the knees on the medial longitudinal plantar arch; the results showed that this distance had a significant effect on the height of the medial longitudinal plantar arch.

Previous studies have reported that changes in body alignment may have a significant effect on specific joints and muscles during squatting. Frey et al. ${ }^{13}$ reported a significant difference in hip and knee torque according to knee position in the sagittal plane during squatting. In their study, knee torque was increased more than hip torque when the knees were farther from the ends of the feet, while the knee

Table 2. The height of medial longitudinal plantar arch between three squatting methods $(\mathrm{N}=18)$

\begin{tabular}{cccccc}
\hline & Sitting position & A condition & B condition & C condition & $F$ \\
\hline $\begin{array}{c}\text { Height of medial longitudinal } \\
\text { plantar } \operatorname{arch}(\mathrm{cm})\end{array}$ & $5.51 \pm 2$ & $4.11 \pm 2.4^{\dagger}$ & $4.75 \pm 2.0^{\ddagger}$ & $6.01 \pm 1.9^{\S}$ & 109.107 \\
\hline
\end{tabular}

A condition: Squatting with $2 / 3$ of pelvic width, B condition: Squatting with pelvic width, C condition: Squatting with $4 / 3$ of pelvic width.

${ }^{\dagger}$ Significant differences between $\mathrm{A}$ and B conditions, ${ }^{\star}$ significant differences between $\mathrm{B}$ and $\mathrm{C}$ conditions, ${ }^{\S}$ significant differences between $\mathrm{C}$ and A conditions. 
torque was decreased more than the hip torque when the knees were less distant from the ends of the feet. Another study demonstrated that knee injury could occur if the knees were farther from the ends of the feet during squatting. ${ }^{14}$ These studies suggest that the squatting position can have both positive and negative effects, and it is necessary for individuals to perform squats in the correct manner.

As an extension of previous studies, we found that a change in the distance between the knees during squatting can induce pronation and supination of the feet. This is important for individuals with pronated or supinated feet who want to strengthen their lower extremity muscles using squats.

Clinicians should consider the possibility of adverse effects when performing squats in patients with abnormal foot alignment. A change in the squatting posture according to the subject's medial longitudinal plantar arch can strengthen the lower extremity muscles, while preventing negative effects on the lower extremity. We propose that when performing squats, the knees of subjects with pronated feet should be farther apart than the pelvic width, or the feet should be maintained in normal alignment using an insole.

This study recruited healthy young subjects. Therefore, it may be difficult to generalize our results to individuals with abnormal alignment of the feet, or to middle-aged individuals who are more likely to have weaker lower extremity muscles. In addition, the participants were not grouped into normal medial longitudinal arch, pes planus, or pes cavus in this study. Further studies should determine the effects of the distance between the knees while performing squats on individuals with abnormal medial longitudinal plantar arch.

\section{CONCLUSIONS}

When squatting was performed with the knees separated by two-, three-, or four-thirds of the pelvic width, the height of the medial longitudinal plantar arch differed significantly. It is important to be aware of the distance between the knees while performing squats, especially in patients with pronated or supinated feet.

\section{Key Points}

Question Can the distance between the knees while performing squats affects the medial longitudinal plantar arch?

Findings The height of medial longitudinal plantar arch differed significantly when squatting was performed with the knees separated by two-, three-, or four-thirds of the pelvic width.
Meaning Changing the distance between the knees while squatting affects the medial longitudinal plantar arch. Clinicians should educate their patients on the correct squat position.

\section{Article information}

Conflict of Interest Disclosures: None.

Funding/Support: None.

Acknowledgment: None.

\section{REFERENCES}

1. Yack HJ, Collins CE, Whieldon TJ. Comparison of closed and open kinetic chain exercise in the anterior cruciate ligament-deficient knee. Am J Sports Med. 1993;21(1):49-54.

2. Fry AC, Smith JC, Schilling BK. Effect of knee position on hip and knee torques during the barbell squat. $J$ Strength Cond Res. 2003;17(4):629-633.

3. Cibulka MT. Low back pain and its relation to the hip and foot. J Orthop Sports Phys Ther. 1999;29(10):595601.

4. Rose GK, Weltone EA, Marshall T. The diagnosis of flat foot in the child. Bone Joint Surg Br. 1985;67(1):71-78.

5. Brukner P. Anterior knee pain. Aust Fam Physician. 1996;25(6):908-911; 914.

6. Valmassy RL. Clinical biomechanics of the lower extremities. St. Louis: Mosby; 1996.

7. Khamis S, Yizhar Z. Effect of feet hyperpronation on pelvic alignment in a standing position. Gait Posture. 2007;25(1):127-134.

8. Park JW, Nam KS. Change of fractional anisotropy in the left inferior frontal area after motor learning. J Kor Soc Phys Ther. 2010;22(5):109-115.

9. Kim HS. A comparative analysis through EMG of the lower half of the body when doing full and half squats. Master's thesis. The Graduate School, Pukyong National University; 2014.

10. Escamilla RF, Fleisig GS, Zheng N, Barrentine SW, Wilk KE, Andrews JR. Biomechanics of the knee during closed kinetic chain and open kinetic chain exercises. Med Sci Sports Exerc. 1998;30(4):556-569.

11. Escamilla RF, Fleisig GS, Lowry TM, Barrentine SW, Andrews JR. A three-dimensional biomechanical analysis of the squat during varying stance widths. Med Sci Sports Exerc. 2001; 33(6):984-998.

12. Palmitier RA, An KN, Scott SG, Chao EY. Kinetic chain exercise in knee rehabilitation. Sports Med. 1991;11(6):402-413. 
13. Fry AC, Smith JC, Schilling BK. Effect of knee position on hip and knee torques during the barbell squat. $J$ Strength Cond Res. 2003;17(4):629-633.
14. Lee SW, Moon YJ, Eun SD. The kinematic differences and distribution of joint Loads according to squat type. Korean J Sport Sci. 2011;22(1):1674-1684. 